\title{
Appendiceal Mucocele Detected under Treatment of Ulcerative Colitis
}

\author{
Rohta Noaki ${ }^{a}$ Hidejiro Kawahara ${ }^{a}$ Kazuhiro Watanabe \\ Susumu Kobayashi ${ }^{\mathrm{a}}$ Kan Uchiyama ${ }^{\mathrm{b}}$ Katsuhiko Yanaga ${ }^{c}$ \\ Departments of a Surgery and ${ }^{\mathrm{b}}$ Medicine, Kashiwa Hospital, Jikei University School \\ of Medicine, Chiba, and 'Department of Surgery, Jikei University School of \\ Medicine, Tokyo, Japan
}

\section{Key Words}

Appendiceal mucocele $\cdot$ Ulcerative colitis

\begin{abstract}
A 33-year-old female patient with ulcerative colitis was referred to our outpatient clinic in January 2008 with right lower abdominal pain without bloody diarrhea. Colonoscopy found mild proctosigmoiditis and a submucoal tumor with a maximal diameter of $5 \mathrm{~cm}$ in the cecum. Computed tomography revealed a large, hypodense, cystic cylindrical structure extending to the pelvic space. For severe pain, she underwent partial resection of the cecum including the tumor in March 2008. Intraoperatively, the vermiform appendix was swollen like a sausage and compressing the cecum, which accounted for what appeared to be a submucosal tumor like a volcano by endoscopy. Lymphadenectomy was not performed because malignancy was not suspected. In the surgical specimen, the vermiform appendix was spindle-shaped and contained a large quantity of viscous liquid. Postoperative pathological diagnosis was mucinous cystadenoma, and no cancer cells were present in the viscous liquid within the vermiform appendix. The patient left the hospital 7 days postoperatively, and her colitis remains in remission without any complications.
\end{abstract}

\section{Introduction}

When a mass is palpable or detected incidentally by imaging studies in the lower right abdomen in a patient without a history of appendectomy, the possibility of appendiceal mucocele (AM) needs to be considered. AM is a descriptive term for mucinous distension of the appendiceal lumen regardless of the underlying pathology. Four causal pathologic conditions have been reported: retention cyst, mucosal hyperplasia, cystadenoma (or mucinous tumor of unknown malignant potential) and cystadenocarcinoma [1]. In 
cystadenomas, the most common form, luminal dilatation can reach up to $6 \mathrm{~cm}$ and is associated with appendiceal perforation in $20 \%$ of cases, resulting in mucinous spillage into the periappendicular area and peritoneal cavity $[2,3]$. Histological examination of the mucus does not reveal any neoplastic cells, and appendectomy is usually curative [4]. Although underlying malignancies in a mucocele are important for the management, preoperative diagnosis of the etiology of AM is difficult on imaging studies [5]. AM can present in a variety of clinical conditions, but concomitant ulcerative colitis (UC) is extremely rare. We herein report such a patient.

\section{Case Report}

A 33-year-old female patient with UC was referred to our outpatient clinic in January 2003. Disease activity was judged moderate by colonoscopy and biopsy. Mesalazine was started orally, and the disease was in remission by May 2003. Since then, she was followed regularly in our department. In January 2008, she was referred again to our outpatient clinic with right lower abdominal pain without bloody diarrhea. Colonoscopy revealed mild proctosigmoiditis and a submucosal tumor with a maximum diameter of $5 \mathrm{~cm}$ in the cecum (fig. 1). As the cecum was occupied by the large tumor, the orifice of the vermiform appendix was observed like a volcano. Endoscopic biopsy failed to give histological diagnosis. Computed tomography (CT) revealed a large, hypodense, cystic tube-like structure extending into the pelvic space (fig. 2). An abdominal sonography revealed peculiar onion-skin-like internal echogenicity in the right lower abdomen (igg. 3 ). Laboratory tests including carcinoembryonic antigen were unremarkable.

Since the dull pain was severe, informed consent was obtained and partial resection of the cecum including the tumor was performed in March 2008. Intraoperatively, the vermiform appendix was swollen like a sausage and compressing the cecum, which accounted for what appeared to be a submucosal tumor simulating a volcano by endoscopy. Lymphadenectomy was not performed because malignancy was not suspected. In the surgical specimen, the vermiform appendix was spindle-shaped, measured $12 \mathrm{~cm}$ in length and $3 \mathrm{~cm}$ in diameter (fig. 4) and was filled with a large quantity of viscous liquid (fig. 5). Postoperative pathological diagnosis was cystadenoma, and no cancer cells were present in the viscous liquid within or the vermiform appendix or its wall. The patient left the hospital 7 days postoperatively, and her colitis has been in remission without any complication.

\section{Discussion}

$\mathrm{AM}$ is a rare pathology of the appendix characterized by a cystic dilatation of the lumen with stasis of mucus. Its incidence ranges between 0.2 and $0.3 \%$ of all appendectomies, with a higher frequency in females and in patients more than 50 years of age [6]. Symptoms of AM are nonspecific, but even large lesions up to $4 \mathrm{~cm}$ are symptomatic in $75 \%$ of patients. The most common presentation is right lower quadrant pain, similar to acute appendicitis; a palpable mass can be found in $50 \%$ of cases, whereas urinary dysfunction or hematuria is rarely associated [7]. The diagnosis is difficult on preoperative imaging studies; up to $60 \%$ are diagnosed during operations for other conditions [8]. Variable significance of ultrasonography and CT have been reported $[5,9,10]$ : ultrasonography can show an elongated hypoechoic mass that is not typical of a cyst. Fine echo spots and/or concentric echogenic layers within the cystic mass, so-called onion skin, are thought to be specific signs for AM [5]. Small lymph nodes or soft tissue in the surrounding fat on CT may suggest the possibility of malignancy $[9,10]$.

In our patient, as she had been under treatment of UC for more than 5 years, AM was detected in the right lower abdomen for severe dull pain. The question arises whether there is a direct link between inflammatory bowel disease (such as UC) and AM. Some authors have suggested that the vermiform appendix or the appendiceal orifice might be involved in UC $[11,12]$. Although the relation between AM and UC still remains unclear 


\begin{tabular}{r|l|l|l} 
Case Reports $/ \mathrm{h}$ & $\begin{array}{l}\text { Case Rep Gastroenterol 2009;3:360-365 } \\
\text { D0I: 10.1159/000242475 }\end{array}$ & Published online: November 21, 2009 & $\begin{array}{l}\text { O 2009 S. Karger AG, Basel } \\
\text { ISSN 1662-0631 } \\
\text { www.karger.com/crg }\end{array}$ \\
\hline
\end{tabular}

$[13,14]$, inflammation in the cecum may facilitate obstruction of the appendiceal lumen as suspected in our patient.

Fig. 1. Colonoscopy found a submucoal tumor simulating a volcano with a maximum diameter of $5 \mathrm{~cm}$ in the cecum.

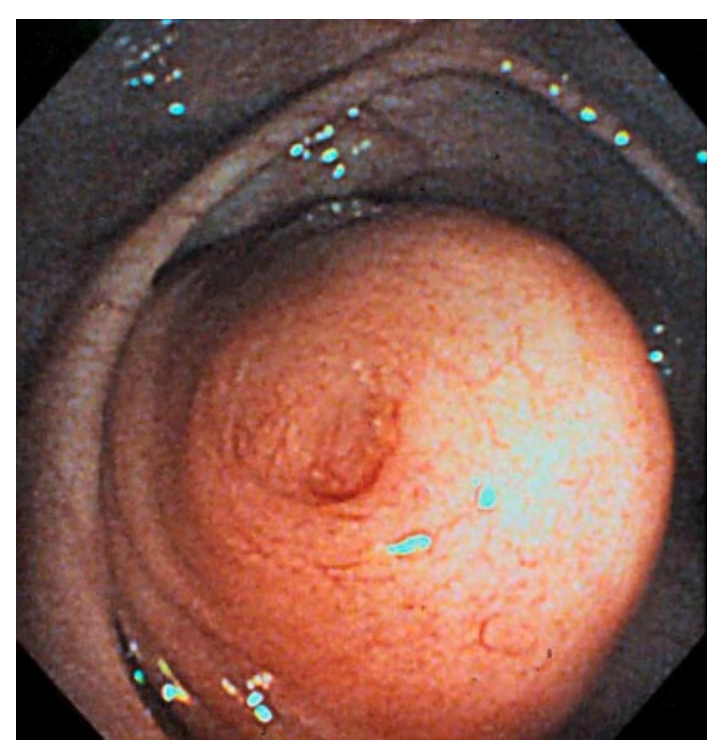

Fig. 2. Abdominal CT revealed a large, hypodense, cystic tube-like structure extending into the pelvic space.

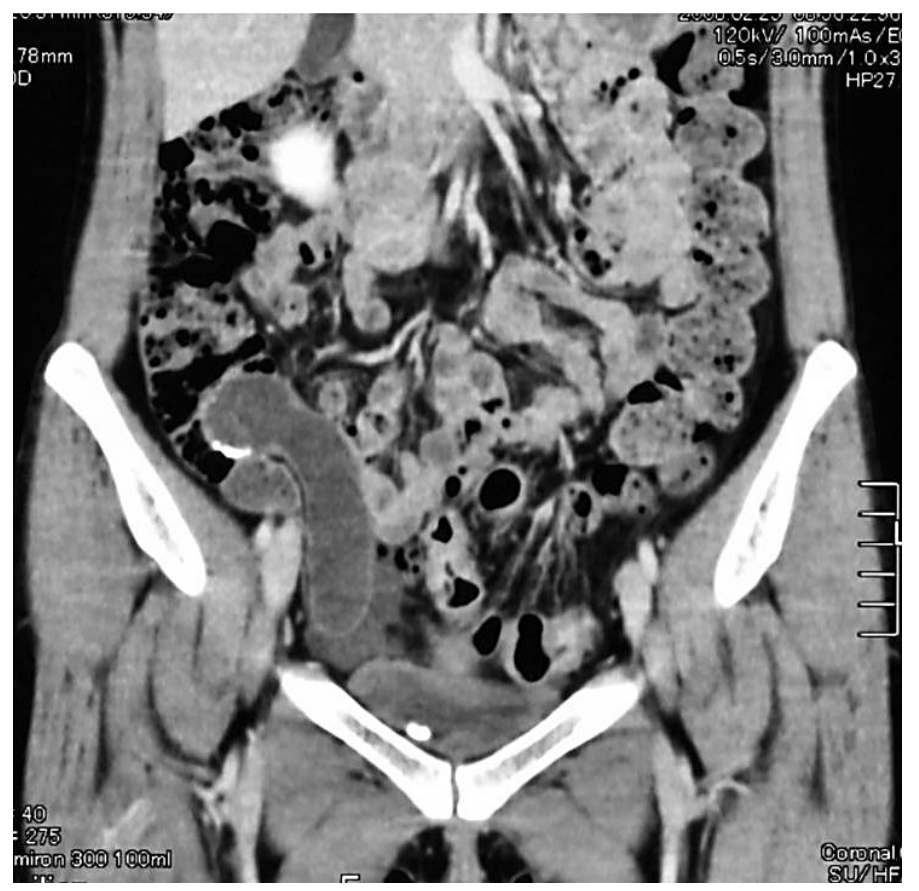




\begin{tabular}{r|l|l|l} 
Case Reports $/ \mathrm{h}$ & $\begin{array}{l}\text { Case Rep Gastroenterol 2009;3:360-365 } \\
\text { D0I: 10.1159/000242475 }\end{array}$ & Published online: November 21, 2009 & $\begin{array}{l}\text { O 2009 S. Karger AG, Basel } \\
\text { ISSN 1662-0631 } \\
\text { www.karger.com/crg }\end{array}$ \\
\hline
\end{tabular}

Fig. 3. Abdominal sonography revealed peculiar internal echogenicity, onion skin sign, in the right lower abdomen.

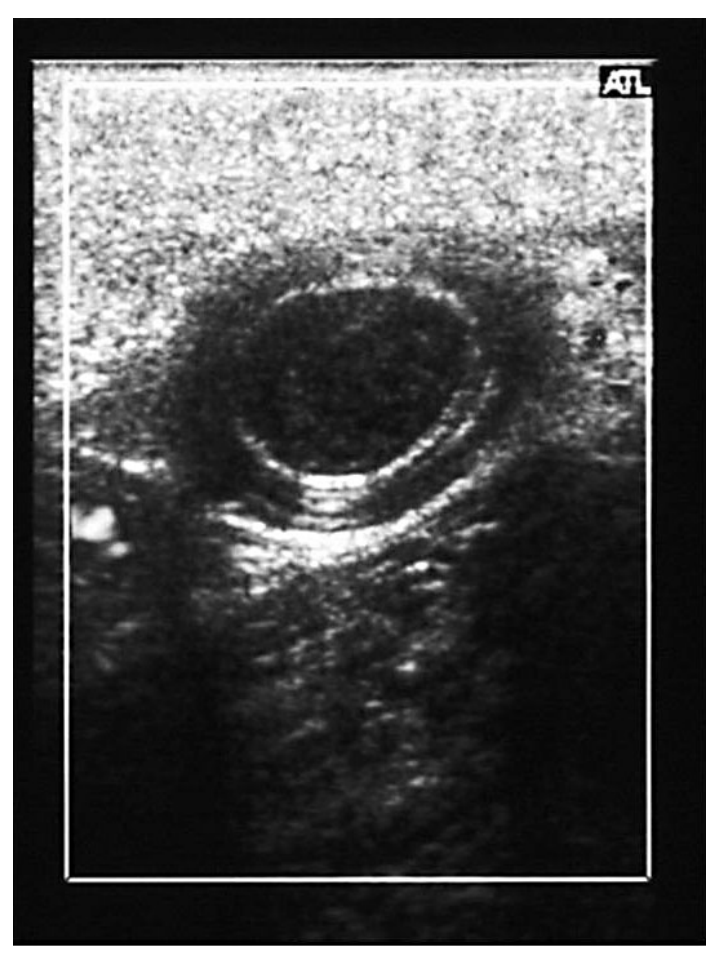

Fig. 4. Intraoperative finding. A giant appendix measuring $12 \mathrm{~cm}$ in length and $3 \mathrm{~cm}$ in diameter.

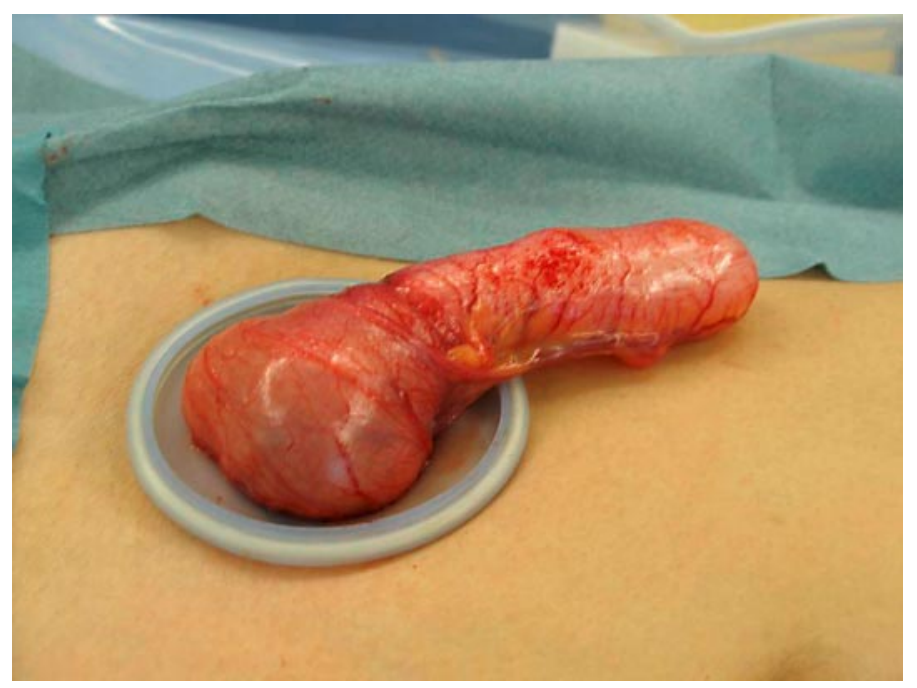


Case Reports in | Case Rep Gastroenterol 2009;3:360-365 Gastruenterology

Fig. 5. Resected specimen. A large quantity of viscous liquid was present in its lumen.

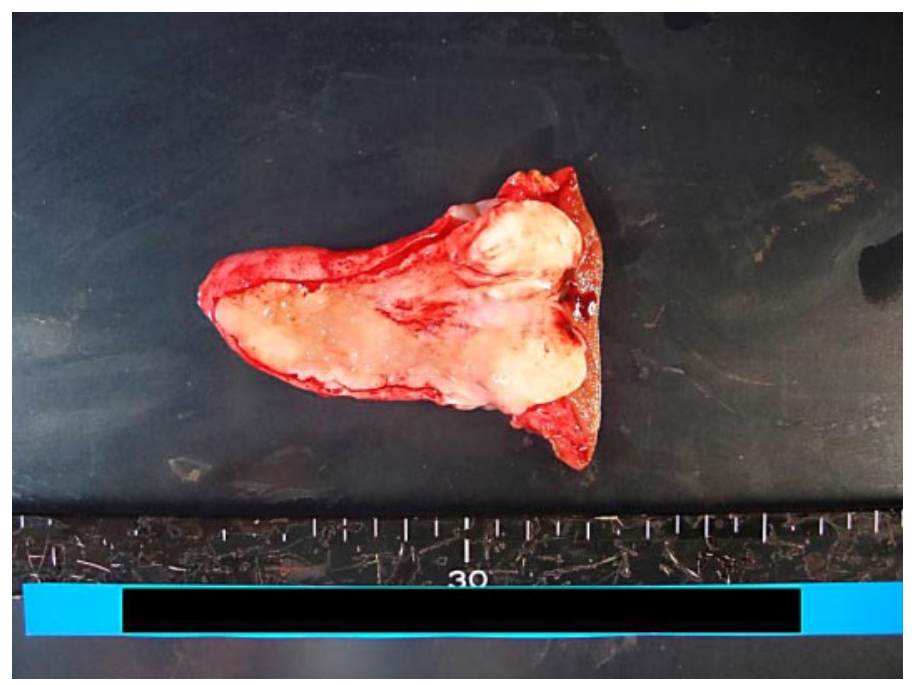




\section{References}

-1 Sasaki K, Ishida H, Komatsuda T, Suzuki T, Konno K, Ohtaka M, Sato M, Ishida J, Skai T, Watanabe S: Appendiceal mucocle: sonographic findings. Abdom Imaging 2003;28:15-18.

2 Crawford J: Tumors of the appendix; in Cotran R, Kumar V, Robblins S (eds): Pathologic Basis of Disease. Philadelphia, Saunders, 1994, pp 824-825.

-3 Landen S, Bertrand C, Maddern GJ, Herman D, Pourbaix A, de Neve A, Schmitz A: Appendiceal mucoceles and pseudomyxoma peritonei. Surg Gynecol Obstet 1992;175:401-404.

4 Gibbs NM: Mucinous cystadenoma and cystadenocarcinoma of the vermiform appendix with particular reference to mucocele and pseudomyxoma peritonei. J Clin Pathol 1973;26:413-421.

5 Caspi B, Cassif E, Auslender R, Herman A, Hagay Z, Appelman Z: The onion skin sign: a specific sonographic marker of appendiceal mucocele, J Ultasound Med 2004;23:117-121.

6 Aho AJ, Heinomen R, Lauren P: Benign and malignant mucocele of the appendix. Acta Chir Scand 1973;139:392-400.

7 Merran S: Tumeur muco-sécrétante de l'appendice (mucocèle appendiculaire). Presse Med 1997;26:933.

-8 Lakatos PL, Gyori G, Halasz J, Fuszek P, Papp J, Jaray B, Lukovich P, Lakatos L: Mucocele of the appendix: an unusual cause of lower abdominal pain in a patient with ulcerative colitis: a case report and review of literature. World J Gastroenterol 2005;11:457-459.

\9 Pitiakoudis M, Argyropoulou PI, Tsaroucha AK, Prassopoulos P, Simopoulos C: Cystadenocarcinoma of the appendix: an incidental imaging finding in a patient with adenocarcinoma of the ascending and the sigmoid colon. BMC Gastroenterol 2003;3:30.

10 Pickhardt PJ, Levy AD, Rohrmann CA Jr, Kende AI: Primary neoplasms of the appendix: radiologic spectrum of disease with pathologic correlation. Radiographics 2003;23:645-662.

11 Matsumoto T, Nakamura S, Shimizu M, Iida M: Significance of appendiceal involvement in patients with ulcerative colitis. Gastrointest Endosc 2002;55:180185.

-12 Jo Y, Matsumoto T, Yada S, Nakamura S, Yao T, Hotokezaka M, Mibu R, Iida M: Histological and immunological features of appendix in patients with ulcerative colitis. Dig Dis Sci 2003;48:99-108.

13 Zannoni U, Masci C, Bazzocchi R, Gandolfo F, Pezzi A, Alampi G, Biasco G: Cancer of the appendix in long-standing ulcerative colitis: a case report. Tumori 1997;83:958-959.

14 Odze RD, Medline P, Cohen Z: Adnocarcinoma arising in appendix involved with chronic ulcerative colitis. Am J Gastroenterol 1994;89:1905-1907. 